\title{
IGREJAS, INSTITUIÇÕES RELIGIOSAS E A ECONOMIA DO COMUM NA AMAZÔNIA
}

\section{CHURCHES, RELIGIOUS INSTITUTIONS AND THE ECONOMY OF \\ THE COMMON IN THE AMAZON}

Juliana Carvalho Brandão ${ }^{1}$

Harley Silva ${ }^{2}$

\section{RESUMO}

Este trabalho discute a atuação de instituições religiosas, em especial da Igreja Católica Apostólica Romana, enquanto elementos centrais de locais onde emergem relações sociais de produção e reprodução e gestão de recursos de modo comunitário na Amazônia. O estudo analisa, entre outros aspectos históricos e sociais, uma experiência na cidade de Abaetetuba, no Estado do Pará, na paróquia Cristo Redentor. Ali, foi possível observar práticas do fazercomum e o papel do compartilhamento e da reciprocidade na vida material da comunidade, e onde se estabeleceu uma nova dinâmica na economia local a partir da festividade do "Festival do açaí". É intenção deste trabalho a compreensão de como práticas e espaços da vida religiosa na Amazônia articulam relações de produção social de economias camponesas e áreas urbanas às cadeias de circulação de alcance local.

PALAVRAS-CHAVE: Economia do Comum; açaí, Abaetetuba, instituições

\begin{abstract}
This work discusses the role of religious institutions, especially the Roman Catholic Church, as central elements of places where social relations of production and reproduction and resource management in a community way emerge in the Amazon. The study analyzes, among other historical and social aspects, an experience in the city of Abaetetuba, in the State of Pará, in the parish of Cristo Redentor. There, it was possible to observe practices of doing-common and the role of sharing and reciprocity in the material life of the community, and where a new dynamic was established in the local economy from the festivity of the "Açaí Festival". It is the intention of this work to understand how practices and spaces of religious life in the Amazon articulate relations of social production from peasant economies and urban areas to chains of circulation of local scope.
\end{abstract}

KEYWORDS: Economy of the Commons; açaí; Abaetetuba; institutions

\footnotetext{
${ }^{1}$ Mestranda no Programa de Pós-Graduação em Economia da Universidade Federal do Pará (UFPA). Bacharel em Ciências Econômicas na Universidade Federal do Pará (UFPA). E-mail: julianacbrand@gmail.com ${ }^{2}$ Doutor em Economia pela Universidade Federal de Minas Gerais (UFMG). Docente da FACECONUFPA. PPGE-UFPA. Email: harleysilva@gmail.com
} 


\section{INTRODUÇÃO}

Enquanto espaços coletivos de relações de troca, de base afetiva, as igrejas católicas na Amazônia formam ritos e hábitos, característicos de economias onde há práticas do comum, em contraposição às práticas organizadas pela propriedade privada, à iniciativa individual, exploração do trabalho e apropriação privada dos excedentes econômicos. Esse trabalho examina a validade desta hipótese, tratando especificamente de práticas vivenciadas na Paróquia Cristo Redentor, no município de Abaetetuba, no estado do Pará.

O trabalho discute o fato de que, dadas as condições ambientais, históricas, e à formas de sociabilidade peculiares da região, é possível perceber que instituições religiosas na Amazônia cultivam e organizam em muitos casos relações sociais de produção e reprodução, e gestão de recursos de modo comunitário. Em tais situações, os laços religiosos recorrem a práticas de fazer-comum no qual o compartilhamento e a reciprocidade (Tonucci Filho, 2021) exerce papel concreto na produção da vida material local. A partir de uma experiência da cidade de Abaetetuba-Pará, procuraremos compreender de que maneira práticas e espaços da vida religiosa na Amazônia articulam relações de reprodução social de economias camponesas e espaços coletivos em vilarejos e áreas urbanas à cadeias de circulação de alcance local.

Ao incluir em seus ritos e sociabilidade cotidiana oportunidades para promover práticas autônomas e coletivas de produção, as instituições religiosas na Amazônia abrigam modalidades da vida econômica que o debate teórico sobre o comum, nas últimas décadas, chamou atenção de movimentos anticapitalistas e democráticos. Esse debate e as práticas dos movimentos sociais correlatos evocam formas de fazer a vida econômica que se afastam da lógica da mercadoria. Esta lógica, por outro lado, tem impregnado praticamente todas as esferas da vida no mundo contemporâneo (Tonucci Filho, 2021; De Angelis,2007), e que são marcadas pela racionalidade neoliberal (Dardot, Laval 2017).

$\mathrm{Na}$ Amazônia, temos casos bastante numerosos de agremiações religiosas as quais assumem em termos locais o papel de elemento desse afastamento ou mesmo ruptura com a lógica neoliberal. Entre estes casos, se destaca a atuação da Comissão Pastoral da Terra, criada pela Igreja Católica e que representa anseios de transformação social, auxiliando o processo de organização de defesa do campesinato nos conflitos agrários que envolvem a expropriação da terra (Ferreira e Venturelli,2015). Sua atuação permitiu a criação do Movimento dos Trabalhadores Rurais Sem Terra, importante marco na luta pela reforma agrária. 
Existem, portanto, duas frentes de atuação da tradição religiosa católica na Amazônia, nas quais podemos perceber diálogo com o debate do comum, enquanto crítico da ideologia individualista possessiva. Por um lado, a promoção de feiras, festividades com práticas de produção coletivas. De outro, a defesa e organização da luta pela reforma agrária e contra as injustiças sociais. São atuações importantes e cuja compreensão contribui aos estudos sobre os comuns na Amazônia. Nos interessa discutir, e tentar esclarecer a dimensão econômica de ambas as atuações, e ainda seu ajuste importante com as condições de permanência do bioma amazônico, além de todos os seus desdobramentos ambientais e climáticos, que ultrapassam o escopo desse trabalho.

\section{A crítica da propriedade privada e o comum nas instituições religiosas}

Dardot e Laval (2017) debatem a existência de tradições religiosas cristãs cujos princípios são afins à uma vida material baseadas na noção do "comum". Desde o chamado cristianismo primitivo, praticado pelos primeiros adeptos da religião e narrado nos Atos dos Apóstolos, até um amplo conjunto doutrinário que permaneceu chave para a doutrina da Igreja até a Idade Média. Segundo estes autores, a prática cristã dos primeiros séculos se aproximou de elementos da filosofia grega e latina, em especial da obra de Platão e Aristóteles, moldando um pensamento político-teológico do bem comum expresso por Santo Agostinho, e aprofundado por pensadores medievais como Abelardo. Essa tradição, contribuiu para uma desidentificação entre as práticas comunitárias em razão de sua espiritualização do comum numa visão de bem comum centrada nas questões espirituais cristãs. Entretanto, nela permaneceu a ênfase do sentido comunitário da vida material, contrária à visão individualista e - no limite - à formação de economias controladas pela propriedade privada da terra.

É verdade que desde a filosofia medieval europeia se desenvolveram tendências de cujo cerne procedeu a justificação da propriedade, em particular da obra de São Tomás de Aquino. Esse autor associou a racionalidade humana como dom de Deus a um "direito estável e perpétuo de possuir" coisas exteriores ao homem. Na sua obra tratou também de ligar o trabalho do indivíduo e a apropriação individual dos seis resultados, algo que seria fundamental na argumentação dos pensadores burgueses a partir de Locke e dos jusnaturalistas, como Grotius (Dardot e Laval, 2017) ${ }^{3}$. Em outra direção, mas dentro do catolicismo, as práticas comunitárias,

\footnotetext{
${ }^{3}$ Ver capítulo 6. O direito de propriedade e o inapropriável.
} 
posses não privadas e compartilhamento igualitário do produto do trabalho foi fundamental na sociabilidade católica de mosteiros e abadias medievais.

Algumas regras monásticas chegaram a tratar a inclinação à posse individual mais singela como um vício, e a posse comum de terras e recursos como uma determinação divina. Não é de estranhar, portanto, que as lutas sociais da Europa medieval e moderna contra a emergência de sociedades de mercado ordenadas por instituições privatistas, tenham líderes e movimentos religiosos contrários à propriedade privada, à expropriação de camponeses e artesãos e à proletarização do trabalho. Foi assim nas guerras camponesas na Alemanha do séc. XVI (Araújo Caldas 2018); na guerra civil inglesa do séc XVII (Hill 1987) e até mesmo na experiência colonial, com a assim chamada república guarani, nas missões jesuíticas do Paraguai (Dardot e Laval 2017), chegando ao chamado socialismo cristão do séc. XIX (Cort 2020).

O debate promovido desde 2015 sob os auspícios do Vaticano, na chamada "economia de Francisco" (Lisboa,2020), e na encíclica Laudato Si (LS), contribuiu para uma renovação do debate da Igreja em torno dos dilemas sociais e da crise ambiental. Ao promover um diálogo com economistas acerca do que se denomina "nossa casa comum", o papado de Francisco ao mesmo tempo que dialoga com a tradição de uma sintonia com a Doutrina Social da Igreja Católica, procura fazer uma discussão sobre o futuro. $\mathrm{O}$ objetivo desta empreitada parece ser recolocar de modo explícito a Igreja e o catolicismo no enfrentamento de disfunções das economias industriais de mercado, marcadas por consumismo e imediatismo.

A centralização da filosofia cristã da encíclica Laudato Si se baseia no bem-comum, com condenação da depredação dos recursos da terra, evoca uma economia do "comum", que não confia cegamente na mão invisível do mercado, mas sim que coloca o dinheiro e os bens produzidos a serviço da comunidade, com justiça social e contra a desigualdade social. Cabe à igreja fomentar ambientes em que possa haver esse regresso à simplicidade (Lisboa,2020), bem como ampliar a divulgação da economia de Francisco em suas comunidades e instituições.

O enraizamento cultural das instituições religiosas confere à sua atuação características peculiares de acordo com o ambiente que estão envolvidas. Isso pode ser observado pela forma como os ritos acontecem, em festivais e festividades regados a produtos da terra, que são chamados cada vez mais de "dádivas do território", com relações de laços de afeto. Como dito anteriormente, existe uma tradição cristã que influencia as práticas e o modo de vida dessas 
comunidades, recentemente influenciadas também pela filosofia do bem-comum citada na economia de Francisco. A centralização na dimensão ecológica da encíclica é especialmente importante para a Amazônia, cujos conflitos de propriedade têm participação das igrejas, especialmente pela Comissão Pastoral da Terra.

Na Amazônia, em função das condições históricas de permanência de amplas áreas que não configuram propriedade privada, é possível observar formas coletivas de uso e posse da terra (Almeida, 2004). Existe uma pluralidade fundiária a ser considerada quando se fala de defesa da terra, inclusive não-mercantis. O modo de intervenção de instituições religiosas em defesa do campesinato no centro dos conflitos agrários tem o caráter filosófico cristão com a práxis materialista, fornecendo um tipo de resistência ao individualismo possessivo da visão ocidental da institucionalização da propriedade privada. Esse individualismo possessivo, de acordo com Tonucci Filho (2021), coloca os interesses individuais como superiores aos coletivos, limitando os direitos de propriedade.

A atuação de organizações religiosas como a Comissão Pastoral da Terra tem sido importante para a permanência e defesa dessas formas de uso da terra e organização de economias locais, especialmente na Amazônia, como um elemento central na resistência das lutas do campo que envolviam indígenas e posseiros. No que diz respeito à propriedade privada, é preciso atentar aos registros da CPT através dos Cadernos Conflitos do Brasil, onde foram registradas as lutas no campo brasileiro. Os cadernos possuíam temáticas sobre terra, água, trabalho, e outros, discorrendo sobre conflito de classes e demais conflitos sociais que incluíam a reforma agrária. Dentre eles, destacam-se os "conflitos por terra", concernentes a ações de resistência pela posse, uso e propriedade da terra (Ferreira e Venturelli,2015).

A CPT reuniu registros sobre os conflitos agrários nos seus Cadernos - conflitos no Campo Brasil, e constatou que houveram entre os anos de 1985 e 2015, 23079 conflitos por terra no Brasil. Durante o período analisado, os governos petistas concentraram 48,8\%, possivelmente devido ao abandono da reforma agrária, bem como atuarem em direção aos interesses do agronegócio, e também pela regularização da grilagem. Segundo Ferreira e Venturelli (2015), o agronegócio vem suplantando a reforma agrária, avançando de maneira violenta.

Segundo um de seus fundadores, Ivo Poletto, a Comissão Pastoral da Terra - CPT teve origem em uma "geografia eclesial e política" peculiar no quadro dos movimentos, instituições 
e grupos de ação católicos no Brasil. Enquanto as instituições e movimentos católicos nascidos no centro sul e nordeste do país teve como origem o mandato de evangelização em sentido estrito, a CPT "nasceu da prática das igrejas envolvidas pela violência que atingia as comunidades de índios e posseiros da Amazônia. Em termos eclesiais, isso significava o compromisso de uma igreja local com grupos sociais vítimas da violência" (Mitidiero Jr. 2008, p. 150).

Mitidiero (2008), seguindo Poletto (1997), observa que o ambiente de conflitos pela terra, como suporte e condição da permanência e reprodução social dos grupos vítimas de violência, motivou a criação da CPT e por meio dela de construção de uma práxis transformadora cujo objetivo era "atingir todos os estratos institucionais da igreja, principalmente aquele que está mais próximo do povo: a paróquia". Abordada como uma inovação institucional, logo como um esforço de transformação válido tanto para a instituição na qual nasceu quanto para a realidade que a motiva, e a CPT foi concebida e constituída como uma estratégia de transformação social a partir dos níveis sociais mais elementares. Essa transformação deveria ser portanto religiosa mas ao mesmo tempo política e econômica, com atuação das paróquias em defesa do camponês e do trabalhador explorado ou expulso de sua terra.

Os princípios que motivaram a criação da CPT se difundiram na experiência pastoral e eclesiástica da Amazônia e demais regiões do país (Mitidiero 2008). A instituição segue como referência na defesa de direitos sociais no campo na Amazônia, e na organização de diferentes aspectos da vida comunitária católica. Essa atuação tem sido importante na promoção de valores coletivos e nas lutas sociais do campesinato.

A CPT é uma organização com atuação direta na defesa da terra e está presente em muitos lugares na Amazônia apoiando a luta dos trabalhadores rurais. Seu empenho principal é a defesa da permanência na terra de posseiros e acesso à terra de trabalhadores sem-terra nos estados da Amazônia e outras regiões do país. Muitos dos processos de expropriação desses trabalhadores camponeses é feito com base em um ideário de progresso capitalista, cercando comuns e minando práticas sociais e tradições culturais responsáveis por reproduzir comunidades (Tonucci Filho,2021).

A atuação da CPT diz respeito à defesa da organização camponesa do território, a qual para os trabalhadores e trabalhadoras do campo é voltada para suprir as necessidades 
existenciais, e não somente a produção de mercadoria para comercialização, como acontece com o agronegócio. A organização da igreja faz parte de uma organização da existência a partir da percepção do espaço em que se vive, cuja organização é condicionada pela significação que este tem para os seus indivíduos (Cabral, 2021).

O que ocorre no tipo de troca efetuada em algumas instituições religiosas com influência da renovação carismática e teologia da libertação, é a reprodução de uma organização territorial material não-capitalista camponesa, cuja exploração do espaço ao redor voltada para reprodução material e simbólica do mundo camponês. Desse modo, a terra, a força de trabalho e a produção bem como eventuais ganhos de comercialização pertencem à classe camponesa, que mantem o princípio de autogestão dos trabalhadores e trabalhadoras rurais (Cabral,2021).

A noção de propriedade nas instituições e práticas religiosas é muitas vezes reconstituída em termos comunitários, por meio dos ritos e festividades que evocam valores sociais coletivos que hoje são hoje não hegemônicos em função da difusão legal e prática da propriedade privada. Além do abandono dos valores sociais coletivos, a propriedade quando instituída afirma intrinsecamente processos de exclusão, mesmo tratando-se de propriedades públicas, cujo titular é o estado (Tonucci Filho,2021). A liberdade do proprietário privado é exercida a despeito da liberdade de outros agentes, possuindo uma prática política que é potencialmente violenta.

Outras instituições eclesiásticas católicas atuam em causas afins a da CPT, como as pastorais sociais e o Conselho Indigenista Missionário- CIMI. Segundo Perani (2018), o CIMI está presente em todos os Estados da Amazônia e tem o objetivo de fortalecer a atuação em defesa dos povos indígenas e o protagonismo destes na defesa de suas terras e direitos.

Em direção oposta, o fortalecimento e difusão do agronegócio nas últimas três décadas aprofundou os processos de exclusão e conflito no campo. O setor contribuiu para forçar a estrutura fundiária do país na direção da reconcentração da terra, inclusive por meios ilícitos como a grilagem de terras públicas (Pompéia 2021; Alentejano 2020). A lógica do cercamento, presente na história do desenraizamento da economia e instituição da propriedade privada, levada ao extremo no Brasil constituiu as múltiplas formas de expropriação do comum, combatida por novos atores sociais como a Comissão Pastoral da Terra (Ferreira e Venturelli,2015) 
É importante destacar que esse é um processo característico das economias capitalistas. Desde a experiência pioneira na Inglaterra, a transformação do solo em mercadoria em meados do século XVI vem acontecendo associada à violência (Thompson 1998; Tonucci Filho 2021). No Brasil esse histórico também é violento, e por a importância do que foi modificado devido ao papel de agentes religiosos, especialmente a criação da Comissão Pastoral da Terra.

A realidade fundiária brasileira é marcada por desigualdade, ilegalidade e violência. A herança colonial foi renovada no séc XIX pela Lei de Terras de 1850, a qual estabeleceu a propriedade privada a partir do regime colonial de sesmarias, e conservando suas características institucionais e sociais, como a seletividade social anti popular, por ex. Foi um marco para a lógica mercantil na institucionalização da propriedade privada no Brasil, e um passo atrás para a territorialidade, a qual segundo Almeida (2004) é fator de identificação, defesa e força. Aqui, o campesinato se baseia na relação de trabalho familiar. Os conflitos surgem também desse fato ser completamente negligenciado, e vêm sendo comprovados pela CPT desde 1975 (Ferreira e Venturelli,2015), quando defenderam as vítimas do golpe militar. A CPT permitiu através de sua atuação, a criação do Movimento dos Trabalhadores Rurais Sem Terra, além de outros movimentos com o objetivo de promover justiça social no campo.

\section{Atuação da Igreja Católica e economia do comum na Amazônia - Abaetetuba - Pará}

Situada na região do Baixo Tocantins, Abaetetuba possui 160.439 habitantes distribuídos em 87,61 habitantes por $\mathrm{km}^{2}$, localizada a $60 \mathrm{~km}$ da cidade de Belém do Pará. Trata-se do sétimo município mais populoso do estado do Pará, e é formado por dois distritos: Abaetetuba (Sede) e a Vila de Beja, possuindo também uma zona rural composta por ilhas, estradas e ramais (Ferreira,2020). Comunidades quilombolas como São Alto, Baixo Itacuruçá, Campopema, Jenipaúba, Acaraqui, Igarapé São João (Médio Itacuruçá), Arapapu, Rio TauaréAçú, Arapapuzinho e Rio Ipanema, se fazem presentes em aproximadamente 701 famílias, segundo dados da Comissão Pró-Índio de São Paulo.

A delimitação do município com marcada presença da zona rural reflete modos de produção e troca em seu espaço, conectado por núcleos de interação econômica. Feiras e igrejas compõem esses núcleos, organizados de tal modo a cumprir funções sociais específicas de acordo com os hábitos institucionalizados da população que os frequenta. Neste trabalho, foi observada a conexão do núcleo religioso do município de Abaetetuba com os hábitos 
alimentares e cultura de consumo observados na feira da cidade, onde são experimentados múltiplas formas de consumir e efetuar trocas que traduzem a cultura local.

Existe uma forte relação do comércio desenvolvido na Feira com a estrutura econômica do município, cuja pecuária conta com bovinos, suínos e caprinos, comercializados ao ar livre e cuja produção de açaí se destaca como segundo maior produtor de açaí do Pará (Ferreira,2020). O setor terciário predominante da região, juntamente com a pecuária e polo pesqueiro, contribuem juntos para a composição de um município que, com suas 72 ilhas na confluência do Rio Tocantins com o Pará, apresente uma rica e diversa cultura de consumo em festivais e feiras, com núcleos que se conectam pelos rios, confluindo em seus centros comerciais como a Feira de Abaetetuba e as festividades da cidade (religiosas ou não).

A economia do município de Abaetetuba, considerando sua parcela "formal", é concentrada na prestação de serviços à demanda local e microrregional. Considerando a média brasileira, o município possui uma parcela extensa da população no campo: $41,18 \%$ dos habitantes vivem em área rural. O setor terciário corresponde a 82,86\% do PIB, e o município vem experimentando uma transformação nas relações de produção. Essas mudanças têm afetado principalmente os habitantes que se deslocam das áreas ribeirinhas localizadas nas diversas ilhas que formam um complexo hidrográfico de aproximadamente 35 colônias e comunidades rurais (Quaresma et al, 2015). Seu PIB per capita é de R $\$ 9.046,13$, com 93,1\% das receitas oriundas de fontes externas ${ }^{4}$.

É necessário dizer que os hábitos alimentares da população vêm apresentando mudanças (Nascimento e Guerra, 2016) que refletem a redução dos recursos naturais, a diminuição das áreas de produção agrícola e o aumento do valor comercial da produção. Uma decorrência importante desse cenário é a redução da autossuficiência das famílias e o aumento da produção de açaí enquanto elemento gerador de renda. É o caso de comunidades quilombolas como a do baixo Acaraqui, de acesso fluvial, parte do território quilombola das ilhas de Abaetetuba (Nascimento e Guerra, 2016). Trata-se de uma realidade que influencia práticas produtivas e alimentares que irão compor os espaços de circulação e troca no município, conectado pelos rios, tais como as feiras e igrejas. A feira de Abaetetuba, por exemplo, absorve as práticas e cultura alimentar da conexão de mais de de 10 municípios adjacentes, exercendo importante papel como centro de referência para satisfação das necessidades da população.

\footnotetext{
${ }^{4}$ Dados do IBGE em https://cidades.ibge.gov.br/brasil/pa/abaetetuba/historico.
} 
A experiência de interação entre vida religiosa e economia local que é objeto de nossa atenção aqui se localiza no município de Abaetetuba, no Estado do Pará. Trata-se de evento organizado pela Paróquia do Cristo Redentor, no município de Abaetetuba-Pará, que foi denominado Festival do Açaí. O festival do açaí

Ocorreu na Paróquia do Cristo Redentor, no município de Abaetetuba-Pará, parte da Diocese de Abaetetuba, localizada na rodovia Dr. João Miranda, a aproximadamente $2 \mathrm{~km}$ do centro do município. Existe uma experiência de atuação dos agentes da Igreja Católica na promoção de festejos e atividades comunitárias onde há elementos do comum, como ocorreu na festividade a relatada neste estudo, quando mais de 500 pessoas se reuniram em 5 de setembro de 2021. Foram doados alimentos como carnes de caça (capivara), carne bovina, suína e frango por diversas comunidades eclesiais ao redor de Abaetetuba, juntamente com os litros de açaí que deram nome à festividade.

Todo o açaí foi doado por produtores locais, bem como os demais alimentos. O açaí (Euterpe olerácea) faz parte, dentre outras combinações, do binômio "açaí e charque", como é conhecida a carne seca no município e em muitas regiões do Pará. É consumido combinado também com camarões, carne de caça, e farinha de mandioca nos mais diversos espaços, desde quilombos (onde protagoniza o sistema de trocas com peixes e camarões) até feiras e igrejas. No relato feito neste trabalho observou-se a importância do açaí, o qual é comprado por comunidades no próprio município de Abaetetuba (Nascimento e Guerra,2016).

A crescente valorização da produção local do açaí, devido ao crescimento da sua demanda influencia a mudança no desenho da economia de autoconsumo e trocas para a comercialização. A coleta do açaí é uma atividade menos penosa e mais rentável, de acordo com relatos de famílias de comunidades quilombolas de Abaetetuba (Nascimento e Guerra,2016), e as mudanças nas práticas de produção, e o investimento das famílias em atividades com maior interesse econômico e especialização de sua produção refletem os hábitos e relação estreita entre as comunidades e o comércio local,com transações locais de compra e venda de alimentos. A igreja atua nesse ínterim enquanto espaço de trocas e ponto de encontro onde irá emergir elementos de economia do comum a partir da cultura alimentar, e características econômicas das comunidades que formam o público que a frequenta.

A conexão do festival do açaí com a economia local se faz notória quando se consideram aspectos que concernem a economia da região. Trata-se de uma região repleta de comunidades 
tradicionais, as quais se conectam por uma ou mais comunidades eclesiais de base. Eventos como o "Festival do açaí" movimentam essas comunidades, e sua produção de açaí e de carne de caça, que é uma característica peculiar dos hábitos alimentares no município. Abaetetuba é um dos maiores produtores de açaí do estado do Pará, com diferentes tipos de manejo (Nascimento e Guerra.2016). A população local aprecia muito o consumo da polpa do açaí acompanhada de carne de caça, principalmente de capivaras (Hydrochoerus hydrochaeris). Os acompanhamentos formados pelo binômio "açaí e carne" (de caça, carne bovina ou suína) refletem as práticas alimentares da população e fortaleceram perspectiva de um próximo festival, já planejado para o próximo ano.

No caso da festividade que relatamos aqui, os elementos que formaram a festividade incluíram o protagonismo de um produto local, gerador de renda e importante parte da cultura alimentar da região, bem como trocas baseadas em reciprocidade, com objetivos voltados para o bem comum. Vale destaque o fato de que o montante auferido com a venda dos pratos foi utilizado para erguer e reformar o centro que hoje é utilizado para vendas dos produtores locais. A precificação é baseada na capacidade de pagamento da população (Figura 1).

A entrevista cuja fonte deu origem às informações contidas nesse trabalho foram fornecidas pela secretaria da Paróquia Cristo Redentor. Segundo as informações fornecidas ela, foram mais aproximadamente de dez núcleos das comunidades eclesiais que participaram da organização do evento, doando açaí e carnes de caça. Mais de 500 pessoas participaram do evento, evidenciando o fato de que a igreja funcionou como elemento de dinamismo da produção local naquele dia.

Atualmente, as festividades reúnem barracas fixas de 10 produtores locais com as vendas de sua produção. As vendas fazem parte das práticas da paróquia do Cristo Redentor, e reforçam o fazer-comum, com produção que reflete a cultura alimentar das comunidades. Devido a sua regularidade e conexão com diferentes espaços do território de Abaetetuba, as vendas da paróquia, baseadas no poder de pagamento dos fiéis e não raro baseadas em objetivos coletivos (construções, doações), configuram elementos importantes para o estudo da economia do comum no campo e na Amazônia.

Figura 1. Festividade de religiosa na paróquia Cristo Redentor. Novembro, 2021 


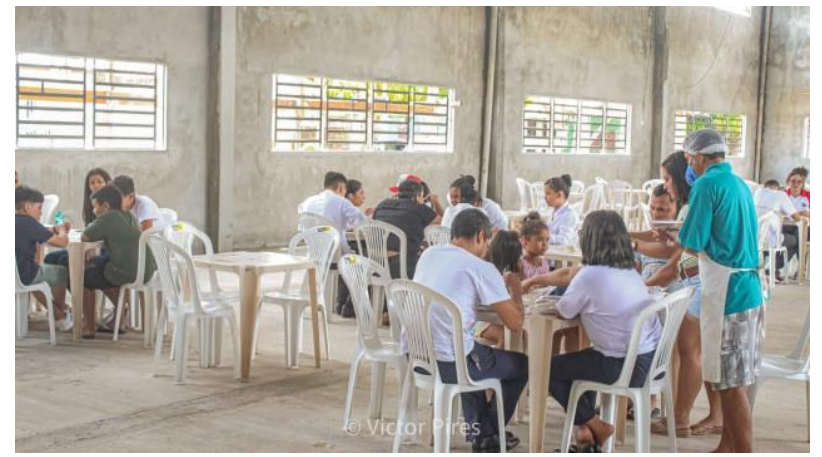

Fonte: Acervo dos autores.

Embora tenha se observado a presença de carne de caça na feira e na festividade religiosa aqui relatada, é necessário observar que muitas vezes a prática é pautada pela necessidade humana de subsistência, permeada pelo respeito à sazonalidade da prática alimentar, como é o caso da forma que a prática se dá em determinado contexto socioeconômico. Abaetetuba reflete o caso de uma institucionalização da cultura alimentar que emerge em ambientes diversos, como é o caso de igrejas e feiras, sendo possível e cabível a reflexão acerca desses hábitos com a necessidade de preservação ambiental dos animais de caça, a sazonalidade das práticas a eles referentes e sua presença na alimentação da população, seja ela em feiras, igrejas e outros espaços de representação cultural.

O encontro da necessidade da população com a disponibilidade de recursos do entorno contribui para a formação dos hábitos a serem formados e reproduzidos, como é o caso da comercialização das carnes de caça nas feiras e sua presença em núcleos de troca, como ocorre no "Festival do Açaí" na paróquia do Cristo Redentor, objeto de estudo deste trabalho. A Paróquia reproduziu em um dia através do festival do açaí, os hábitos de troca de sua feira principal, comercializando açaí e carne de caça, proveniente da produção de suas comunidades predominantemente rurais.

As práticas das instituições religiosas na Amazônia de promoção de feiras e festividades não são recentes: as festividades religiosas são um traço das religiões em geral e do catolicismo em particular. O naturalista Alfred R. Wallace (1823-1913) que esteve na Amazônia no séc. XIX se impressionou com a frequência, duração e engajamento da sociedade local com estes festejos (Wallace 2004). Um século mais tarde, o antropólogo Charles Wagley deixou um vivo relato das festividades de São Benedito no município de Gurupá (Wagley 
1957). Esses festejos, embora possam ser vistos como folguedos ou tempo de não-trabalho, tem significado econômico importante, em particular nos municípios e localidades de pequena população. As festas atraem e reúnem visitantes em momentos bem conhecidos, e esperados, o que movimenta diferentes setores da vida econômica, direta e indiretamente. $\mathrm{O}$ exemplo mais óbvio é a importância econômica da festa do Círio de Nazaré, em Belém, de enorme significado no calendário do comércio e serviços do município (Costa et al 2008).

Ainda atualmente, as festividades religiosas na Amazônia se conectam a relações sociais peculiares dos hábitos do campesinato na Amazônia. Em muitos casos, as festas incorporaram algum sincretismo religioso, o que ampliou sua apropriação popular. Os eventos conservam também elementos de reciprocidade comunitária articulada à visão cristã de partilha (Custódio et al 2019, Rodrigues 2009; Andrade 2021). Em alguns casos, até mesmo as regras de precificação dos produtos consideram critérios do costumes e do hábito. É característico da reprodução social camponesa a produção para o próprio consumo e a comercialização de excedentes, e de modo secundário a aquisição de mercadorias. Essas práticas econômicas encontram eco e respaldo nos hábitos de instituições várias religiosas católicas.

Segundo Perani (2018), um processo de renovação estrutural das dioceses na Amazônia aproximou a igreja das comunidades mais intensamente. Houve investimento na formação de agentes de pastoral, padres, freiras e outros atores sociais do ambiente católico com o intuito de dar mobilidade ao clero. As igrejas locais passaram a ter mais autonomia, fato que influencia diretamente a promoção de práticas com relações de troca e reciprocidade nas paróquias e dioceses.

Com tais mudanças, a igreja parece buscar acompanhar as mudanças na configuração política e socioeconômica no mundo contemporâneo, e a maneira como essas transformações atingem as comunidades amazônicas, em particular. As relações entre as comunidades, paróquias e dioceses de um mesmo território têm um potencial político de influência, criação e difusão de hábitos de pensamento e ação. As comunidades eclesiais de base (CEBs) ${ }^{5}$, unidades desta religiosidade enraizada, estão muito presentes no território amazônico. As CEBs são comunidades formadas para celebrar os ritos católicos e desenvolver atividades das pastorais

\footnotetext{
${ }^{5}$ Raymundo Heraldo Maués (2010) destacou o papel de comunidades eclesiais de base na mesorregião do nordeste paraense. São comunidades amazônicas re-inventadas por agentes pastorais católicos nos últimos anos, desde a segunda metade do século XX.Além disso, o autor demonstrou haver papel relevante das comunidade entre os camponeses na microrregião de altamira, favorecendo a emergência de novas formas de cidadania (Maués,2012).
} 
sociais (Perani, 2018). O seu padrão de engajamento é orientado por uma religiosidade comunitária que valoriza a solidariedade como virtude cristã.

As mudanças convergem e se fortalecem com a formação de laços sociais comunitários na esfera da reprodução social comunitária, que inclui a produção e circulação de meios materiais de sobrevivência, mas incluem os próprios laços políticos e afetivos que se reforçam nos ritos e festividades. Segundo Maués (2010), o processo de renovação pelo qual a Igreja Católica passou nas últimas três décadas inclui a emergência de novas formas de cidadania, ação política e reciprocidade. Muitas vezes as comunidades influenciam a organização social em mobilizações políticas a partir de uma identidade étnica local, incluindo lutas em torno, por exemplo, de melhorias para o povoado.

As CEBs reproduzem uma forma de operar voltada para a transformação social e à práxis libertadora, influenciando e intervindo em questões materialistas fundamentadas em uma premissa filosófica de contraponto à pobreza e exploração (Feitosa e Silva,2015). A multiplicação desses núcleos nas últimas décadas faz parte de uma macro estratégia de caráter político-territorial para não perder adeptos, ou mesmo retardar o processo das perdas existentes por parte das igrejas evangélicas. Desde os anos 1970 as práticas político-religiosas tem sido implementadas no países subdesenvolvidos da América Latina, em uma referência à ideologia marxista da luta de classes da igreja Católica. A ideia do movimento atual de renovação é atribuir um caráter de novidade capaz de manter os fiéis nas igrejas sem perder os fundamentos da teologia da libertação.

A intervenção social das CEBS é orientada pela Teologia da Libertação (TL), e os agentes da Igreja Católica possuem o papel de forjar as comunidades em "comunidade social num sentido social da evangelização", inventando a comunidade e o quilombo, estimulada a lutar por seus direitos. No que diz respeito à circulação de alimentos e produção local, temos aí um exemplo de fortalecimento da identidade cultural de uma comunidade em um determinado território, promovido por uma CEB. Atualmente, o engajamento político visando a transformação social se combina à Renovação Carismática, sem perder os elementos fundantes das Comunidades Eclesiais de Base (Feitosa e Silva.2015).

A atuação de uma CEB permite a menção da chamada "antropologia da territorialidade", pois sempre que é inventada uma comunidade, com sua identidade própria, existe uma complementaridade da historicidade do território onde a CEB atua e os conceitos 
que passam a ser utilizados. Existe na criação de conceitos territoriais uma atividade política que reconhece legalmente o que já existe socialmente (Maués, 2010). A partir da experiência de uma paróquia de Bujaru, Maués (2010) demonstrou como é possível haver mudanças importantes introduzidas pelos agentes da Igreja, e sua relação com os movimentos sociais e associações adjacentes.

\section{CONSIDERAÇÕES FINAIS}

A experiência do "festival do açaí" na cidade de Abaetetuba nos mostra que existe uma possibilidade de subversão da lógica neoliberal da mercadoria, pois promove práticas autônomas e coletivas de produção, longe da racionalidade liberal, cuja precificação se baseia numa lógica de solidariedade.

As igrejas são elementos centrais para o resgate de valores coletivos, e engajam diversas lutas sociais, no combate à lógica individualista dos direitos de propriedade. Nesse intuito, vêm passando por mudanças importantes de suas estruturas, ampliando estruturas eclesiais e pastorais sociais com destaque para o Conselho Indigenista e a Comissão Pastoral da Terra. São mudanças que as tornam multiplicadores de espaços onde se cultiva a lógica da solidariedade e trocas baseadas em costumes.

As pastorais e as comunidades eclesiais de base contribuem enquanto representantes da Igreja Católica nos territórios, com uma visão coletiva de propriedade, ao passo que contribuem com a ruptura da lógica herdade pelo individualismo possessivo característico da instituição da propriedade privada. Atuando em duas frentes de atuação que abrangem promoção de festividades e práticas de produção coletiva, juntamente com a defesa e a organização da luta no campesinato, especialmente a reforma agrária, as instituições religiosas se fazem presente como elementos centrais na luta por justiça social e novos hábitos de produção nos territórios amazônicos.

A mobilização de festas religiosas contribui muito para multiplicar os saberes e movimentar a economia em cidades pequenas, com alto índice de desemprego e com diversos núcleos como colônias e agrovilas nos rios. As igrejas funcionam como propagadoras da economia do comum, difundindo uma cultura e lógica de consumo próprias de um dado território, como acontece em Abaetetuba através da Paróquia Cristo Redentor. 


\section{REFERÊNCIAS BIBLIOGRÁFICAS}

ALENTEJANO, P. A hegemonia do agronegócio e a reconfiguração da luta pela terra e reforma agrária no Brasil. Caderno Prudentino de Geografia, v. 4, n. 42, p. 251-285, 2020.

ALMEIDA, Alfredo W. B. de. Terras tradicionalmente ocupadas: processos de territorialização e movimentos sociais. Revista Brasileira de Estudos Urbanos e Regionais, v. 6, n. 1, 2004.

ANDRADE, Rodrigo Fadul. Festas religiosas, cidades e espaços públicos: apontamentos etnográficos sobre a devoção mariana em três cidades amazônicas. Revista Educação e Humanidades, v. 2(2), 2021.

ARAÚJO CALDAS, Marcos José. Lutero, Müntzer e a Revolução do Homem Comum (1524-1525). Intellèctus, v. 17, n. 2, p. 1-25, 2018.

CABRAL, C.A. A produção da existência e resistência da classe camponesa : uma análise fenomenológica de suas lutas contra a lógica do capital. 1. ed. - Jundiaí [SP] : Paco, 2021.

CACCIAMALI, M. C. A economia informal 20 anos depois. Indicadores Econômicos FEE.1994

COSTA, Francisco A.; DINIZ, Marcelo B.; FARIA, Alexandre M. M. F.; SANTOS, José N. A. COSTA, José A. O Círio de Nazaré de Belém do Pará: Economia e fé. Revista Amazônia: Ciência \& Desenvolvimento. Belém: Banco da Amazônia, v 3(6), 2008.

CORT, John C. Christian Socialism: An Informal History, With an New Introduction by Gary Dorrien. Orbis books, 2020.

CUSTÓDIO, Elivaldo Serrão et al. As práticas culturais/religiosas afroindígenas na Amazônia. Revista Caminhos-Revista de Ciências da Religião, v. 17(1), 2019.

DARDOT, Pierre; LAVAL, Christian. Comum: ensaio sobre a revolução no século XXI. Boitempo Editorial, 2017.

DARDOT, Pierre; LAVAL, Christian. Propriedade, apropriação social e instituição do comum. In: Tempo social, São Paulo, v. 27, n. 1, p. 261-273, 2015.

FERREIRA,G.H.C. VENTURELLI, R.M. A Comissão Pastoral da Terra e os 30 anos de documentação sobre o campo brasileiro (1985-2014). Boletim Campineiro de Geografia. Vol.5, 2015

FERREIRA, Hellen Rosalda da S. Animais Silvestres na Feira de Abaetetuba-Pará: Uma análise à luz da regulamentação ambiental como um instrumento de "conscientização" / Hellen Rosalva da Silva Ferreira. - 2020. Disponível em : http://repositorio.ufpa.br/jspui/handle/2011/13459 
DE ANGELIS, Massimo. The beginning of history: value struggles and global capital. London; Ann Arbor, MI: Pluto, 2007.

HILL, Christopher. O mundo de ponta-cabeça: idéias radicais durante a Revolução Inglesa de 1640. São Paulo: Companhia das Letras, 1987.

LISBOA, A.M. A economia de Francisco. P2P \& Inovação. Vol.6.2020

MACHADO,L.O. Urbanização e mercado de trabalho na Amazônia Brasileira. Cadernos IPPUR.1999

MAUÉS, R.H. Novas formas de afirmação de cidadania na Amazônia Oriental Brasileira: Comunidades Eclesiais de Base (CEBs), camponeses e quilombolas. In Religião, política e cultura na América Latina. Novos Olhares. Editor: Cristian Parker Gumucio. Instituto de Estudios Avanzados Universidad de Santiago de Chile.2012

MAUÉS, R.H. Comunidades "no sentido social da evangelização":CEBs, camponeses e quilombolas na Amazônia Oriental Brasileira. Religião e Sociedade, vol.30 2010

NASCIMENTO,Elio da C. GUERRA,Gutemberg A.D. Do avortado ao comprado: práticas alimentares e a segurança alimentar da comunidade quilombola do baixo Acaraqui, Abaetetuba, Pará . Bol. Mus. Para. Emílio Goeldi. Cienc. Hum., Belém, v. 11, n. 1, p. 225241, jan.-abr. 2016.

NEGRI, Antonio. Comum, entre Marx e Proudhon. Resenha originalmente publicada no Il Manifesto, em 6 maio 2014. Trad. UniNômade. (p.282-286). Disponível em: http:// uninomade.net/tenda/comum-entre-marx-e-proudhon/. Acesso em: 20 jul. 2016. .

NEGRI, A . O comum como modo de produção. Texto originalmente publicado em EuroNomade, em 10 jul. 2016. Trad. prel.: Mario Marino. Original disponível em: http:// www.euronomade.info/?p=7331. Acesso em: 7 nov. 2016.

PERANI,C. A igreja na Amazônia: criatividade, dinamismo e vitalidade. Cadernos do CEAS. $\mathrm{N}^{\circ} 244,2018$

POLETTO, IVO; TERRA, A. a Vida em Tempos Neoliberais. Uma releitura da história da CPT. Comissão Pastoral da Terra, A Luta pela Terra: a CPT. São Paulo; Paulus, 1997.

POMPÉIA, C; Formação política do agronegócio. Ed. Elefante, São Paulo, 2021.

QUARESMA, M.; SOMBRA, D.; LEITE, A.; CASTRO, C. Periodização econômica de Abaetetuba (PA) a partir de sua configuração espacial. Revista Percursos. Vol.16. 2015

RODRIGUES, Carmem Izabel. Festividades mestiças na Amazônia. História revista, v. 14(1), 2009. 
TONUCCI FILHO, J.B.M. Entre o privado, o público e o comum: repensando os direitos de propriedade da terra. Revista Direito e Praxis. Vol. 20. 2021

THOMPSON, E.P. Costumes em comum: estudos sobre a cultura popular tradicional. São Paulo: Companhia das Letras, 1998.

WALLACE, Alfred Russel. Viagens pelo Amazonas e Rio Negro. Edições do Senado Federal ; v. 17. Brasília, 2004.

WAGLEY, Charles. Uma comunidade amazônica: estudo do homem nos trópicos. Brasiliana, 1957.

Artigo recebido em: dezembro/2021

Artigo aceito em: fevereiro/2022 